\title{
EDUCAÇÃO AMBIENTAL E ATIVIDADES LÚDICAS PARA A IDENTIFICAÇÃO DA IMPORTÂNCIA DAS DISTINTAS FORMAS DE VIDA (FAUNA E FLORA)
}

Carla dos Santos Rosário ${ }^{1}$

Resumo: Este trabalho inseriu a Educação Ambiental em um Lar para crianças através da aplicação de atividades lúdicas conjuntamente à implantação de uma horta, objetivando a facilitação do processo da aprendizagem. Constatouse a participação ativa e a internalização do conteúdo, através do desenvolvimento e respeito para com as plantas, animais e reconhecimento da importância das interações entre as diferentes formas de vida, confirmando a potencialidade para aplicação de trabalhos similares. As ações também devem envolver os adultos cuidadores que, por desconhecimento ou inadequado tratamento dado ao assunto, podem levar a desconstrução do que foi compreendido pelas crianças.

Palavras-chave: Educação Ambiental; Atividades Lúdicas; Consciência Ecológica; Formas de Vida.

\footnotetext{
${ }^{1}$ Universidade do Vale do Itajaí. E-mail: carlaspaz@hotmail.com
}

revista brasileira educação ambiental 


\section{Introdução}

A Educação Ambiental é um assunto de reconhecido valor, sendo direito de todos os cidadãos brasileiros o acesso aos conhecimentos, habilidades, valores sociais, atitudes e competências objetivando a qualidade de vida e a sustentabilidade do meio ambiente (BRASIL, 1999). Mesmo possuindo uma Política Nacional específica (Lei oㅜ 9.795/99), a Educação Ambiental muitas vezes acaba sendo tratada de forma superficial, sem foco ou objetivo, tornando o tema sem muita importância e deixado a um segundo plano nos estabelecimentos de ensino e até mesmo nas organizações empresariais. No Brasil a Educação Ambiental (EA) é tratada como um tema transversal, estabelecido pelos Parâmetros Curriculares Nacionais (PCNs), sendo integrada e discutida nas diversas áreas de ensino utilizando-se de temas da realidade cotidiana da sociedade. Conforme a Lei № 9.795/99 (BRASIL, 1999), a Educação Ambiental não deve ser implantada como disciplina específica no currículo de ensino.

Em países como a Finlândia e Austrália a Educação Ambiental é tratada como disciplina muito importante e de interesse coletivo para a sociedade. $\mathrm{Na}$ Finlândia é considerada imprescindível em todos os níveis de escolaridade, levando o país a ser um dos mais elevados no conhecimento e consciência ambiental internacional (EVA-LIISHALLANARO, 2017). Na Austrália o assunto social e ambiental é inserido no currículo escolar como disciplina obrigatória (EDUCAÇÃO AUSTRALIANA, 2017). No Brasil, muitas escolas e instituições (Instituto Verde Escola, - SP; Colégio Unificado - SC; Projeto - Escolas Públicas de Guaxupé - MG) já inseriram a Educação Ambiental como parte de alguma disciplina ou em projetos específicos. Há algum tempo no Brasil discute-se a alteração da lei para a inclusão nas grades curriculares como uma disciplina obrigatória (SAMPAIO; MOURA, 2014; NUNES, 2017). Já Salles (2017), cita que ainda há muito para os docentes compreenderem e desenvolverem sobre Educação Ambiental.

Quanto mais cedo o ser humano aprende a proteger, cuidar, preservar e amar, mais rápido ele desenvolve a aptidão ao bom senso e ao conhecimento crítico sobre a abordagem do que é conservar a natureza na sociedade em que está inserido, sem dificuldades para de fato tornar-se um bom defensor do meio ambiente. Para Salvador et. al. (1999) o vínculo entre aprendizagem, cultura e desenvolvimento, é fundamental para educação. As mudanças de comportamentos ocorrem quando nosso comportamento inato se une com o que aprendemos no meio externo, ensinados pelos nossos pais e pelas escolas que frequentamos. Nós não nascemos com vontade de destruir, desmatar, caçar ou poluir, ao contrário, o comportamento inato é de proteção (proteger). Ao se desenvolver os sensores de vivência do que é certo ou errado com a sociedade em geral, podemos aprender da forma errada, agindo como nossos pais, amigos, colegas, professores ou até mesmo com as instituições que abordam ou agem com a natureza da forma incorreta. 
Segundo Delors (2010) o aprender a aprender pressupõe que a educação seja entrelaçada em quatro categorias de aprendizagem: o aprender a ser; aprender a conviver; aprender a fazer e aprender a conhecer. Essa compreensão implica que o educando deve ser formado em sua integridade com base conceitual de uma cultura consolidada e também deve ser formado para ser capaz de intervir em seu cotidiano.

As crianças têm um senso de direção muito sensível e realista, fácil de compreender o certo e errado. É possível, de uma forma lúdica e prática, conseguirem abordar assuntos que a criança irá absorver e levar como aprendizado para o resto da vida. O trabalho de Educação Ambiental, sem dúvida, promove uma boa formação para consciência ecológica da criança, que se tornará um adulto com ideais e foco, pois, quando aprendemos a proteger qualquer forma de vida, preservar o ambiente e cuidar da natureza, estamos levando para nossas vidas conhecimento e valor moral. É possível se tornar um bom ser humano quando sabemos o valor de cada organismo vivo e da sua importância, sem julgar ou desprezar aquilo que ainda não conhecemos. Neves (2008) relata que na medida em que se estabelece a cultura, a educação vai nascendo diante do conhecimento, crenças, leis, moral, costumes entre outros hábitos adquiridos.

No entanto, para todo trabalho ser realizado efetivamente é necessário que o ambiente coletivo corresponda às expectativas do estudo. Em seu trabalho, Libâneo (2004) cita que é preciso que todos estejam engajados em apreender e ensinar, pois educar é o ingrediente básico para construção da atividade humana.

Os trabalhos de educar e ensinar não são exclusivos e únicos das escolas e instituições públicas e privadas. Mesmo quando temos conhecimento de áreas um pouco distantes da pedagogia formal, podemos ensinar. Precisamos esclarecer que, em todo ou qualquer momento, os seres humanos possuem capacidade de aprendizagem para diversos assuntos até então não abordados. Neste contexto, afirmamos que aprender sobre o meio ambiente é tão importante e satisfatório como aprender qualquer outra disciplina. Portanto, é preciso ensinar para futuramente possuir seres humanos mais conscientizados das melhores condições de vida que podemos conseguir, aprendendo a cuidar de nosso espaço. Quando aprendemos a ser conscientes e ter atitudes que envolvem a melhoria da vida coletiva, aprendemos também a ser pacientes para com as outras pessoas e um pouco mais altruístas.

De acordo com Trilla (1993), todo processo de educação formal ${ }^{2}$ ou não formal $^{3}$ tem intencionalidade (educação intencional), ou seja, ambas estão

\footnotetext{
${ }^{2}$ Educação formal: processo sistemático de escolarização onde a criança aprende sobre todas as disciplinas e temas transversais

${ }^{3}$ Educação não formal: subordinada a objetivos sociais onde a educação ocorre de maneira difusa, ou seja, onde ocorre o processo educativo de forma ampla e direcionada a um tema, como por exemplo, palestras de saúde, sexualidade, meio ambiente, etc.
} 
objetivando o alcance do aprendizado pelo aluno. Já a educação informal não tem intencionalidade (educação não intencional), como por exemplo, a educação construída pelo âmbito familiar ou por cuidadoras, onde nem sempre os pais ou cuidadores agem com a intenção de educar com especificidade. A educação informal é um processo educativo indiferenciado onde a função de educar não é dominante e não tem especificidade.

\section{Objetivos}

\section{Geral}

Promover a Educação Ambiental através da aplicação de atividades lúdicas para a identificação e assimilação da importância da proteção e defesa das distintas formas de vida da fauna e da flora.

\section{Específicos}

- Implantar uma horta através de um contexto aplicativo e pedagógico;

- Ensinar sobre a importância da terra e sua composição;

- Possibilitar a observação dos organismos viventes e visitantes e suas interações;

- Reconhecer as diferentes necessidades diárias de cada hortaliça plantada.

\section{Materiais e Métodos}

Este estudo foi realizado no período vespertino (das $15 \mathrm{~h} 00$ às $17 \mathrm{~h} 40$ horas) somente nas sextas-feiras, com início no mês de agosto de 2017 até o término do mês de novembro deste mesmo ano, no Lar Criança Feliz. O Lar Criança Feliz é um lar temporário que fornece acolhimento para crianças órfãs ou que provisoriamente estão sem a tutela de seus responsáveis. O lar está localizado no município de Itajaí/SC e foi fundado em 01 de fevereiro de 1989, denominado, na época, Associação Lar Criança Feliz (ALCF). Outros dados do Lar Criança Feliz, como por exemplo, metragem (interna e externa), números de cômodos, número de funcionários e de crianças, não foram liberados para publicação devido às restrições legais.

A metodologia utilizada foi baseada nos trabalhos de Marangon (2002), Mendonça (2015) e Telles et al. (2002). As realizações das atividades foram voltadas às brincadeiras e expressões de linguagens por meio de diversos assuntos ambientais relacionados aos animais, plantas, meio ambiente e a elaboração da horta. Todas as atividades estão descritas no cronograma da Tabela 1. Desta forma, o desenho, a pintura, o canto, a dramatização (teatrinho) e o manejo do ambiente foram ferramentas essenciais na construção da Educação Ambiental das crianças do Lar. 
A implantação de uma horta foi essencial para a elaboração de todas as atividades envolvidas, utilizando os meios abióticos e organismos viventes para assimilação e importância da fauna e flora. O espaço reservado para o plantio apresentava $8 \mathrm{~m}$ de comprimento por $1 \mathrm{~m}$ de largura. Para realização da horta foi necessária a aquisição de terra preta, regadores, ferramentas de jardinagem e as mudas de hortaliças. O valor para obtenção e compra dos aparatos foram adquiridos através da arrecadação de dinheiro junto à comunidade local e com parceiros voluntários os quais também ajudaram na montagem da horta. Foram também registradas algumas atividades das crianças para melhores resultados do projeto. As fotos tiradas para registro do trabalho foram obtidas através de um aparelho de telefonia celular da marca ASUS Zen Go Modelo: ZC500TG 2015, e não mostram o rosto de nenhuma criança, conforme as normas da direção do Lar.

\section{Materiais utilizados:}

$\checkmark$ Tintas de tecido, pincel e toalhas de mão;

$\checkmark$ Horta: terra preta, mudas de couve, sálvia, alecrim, alface, cebolinha, rúcula, morango, orégano, pimenta e aparatos para mexer na terra (ferramentas e regadores);

$\checkmark$ Palitos de sorvete, cola, canetinhas, lápis de cor, botões de plástico e folhas sulfite;

$\checkmark$ Papel Crepom colorido, papel A3, cola;

$\checkmark$ Argila, tinta guache e pincel;

$\checkmark$ Terrário: terra preta, areia, areia colorida, aquário de vidro e minhoca;

$\checkmark$ Livro de animais da fazenda (biblioteca do Lar);

$\checkmark$ Livro de animais marinhos (biblioteca do Lar);

$\checkmark$ Cartilha guia de Educação Ambiental A Turma do Zinho (IPEC, 2012);

$\checkmark$ Panfletos educativos para crianças sobre Preservação da natureza e saúde.

\section{Resultados}

Tendo em vista que muitos dos resultados se deram através da elaboração de atividades práticas com confecção de pinturas, desenhos, modelos em argila e a própria implantação e condução da horta, eles serão apresentados na forma de Figuras fotográficas (Figuras 1 a 12), conforme cronograma das atividades realizadas, listadas no Quadro 1. 
Quadro 1: Cronograma das atividades realizadas e os resultados alcançados demonstrados através das Figuras fotográficas correspondentes.

\begin{tabular}{|c|c|c|}
\hline Data & Descrição das atividades realizadas & Resultados \\
\hline $11 / 08 / 17$ & $\begin{array}{l}\text { Pintura em tecido: animais marinhos pintados pelas } \\
\text { crianças em toalhas de mão. Reconhecimentos das figuras } \\
\text { da baleia, golfinho, tartaruga e peixe (atividade realizada a } \\
\text { pedido da direção do Lar). }\end{array}$ & tor \\
\hline $18 / 08 / 17$ & $\begin{array}{l}\text { Repicagem e plantio de mudas de hortaliças nos vasinhos } \\
\text { (couve, sálvia, morango, cebolinha, salsinha e sementes de } \\
\text { cebolinha) e o reconhecimento das minhocas. }\end{array}$ & - \\
\hline $25 / 08 / 17$ & $\begin{array}{l}\text { Início do processo de arrecadação do valor para realização } \\
\text { da horta e preparo da horta (retirada das pedras do local do } \\
\text { plantio). }\end{array}$ & Figura 1 \\
\hline 01/09/17 & $\begin{array}{l}\text { Compra dos aparatos de manutenção da horta (pazinhas e } \\
\text { caixa organizadora), recebimento das mudas (doação) para } \\
\text { o plantio na horta, separação, cuidados e procedimentos } \\
\text { para o plantio. Explicação sobre as lagartas, suas } \\
\text { condições de vida e atividade lúdica (desenho para pintar). }\end{array}$ & Figura 2 \\
\hline 02/09/17 & $\begin{array}{l}\text { Recebimento da terra e implantação da horta (processo de } \\
\text { colocar a terra, plantar e regar). }\end{array}$ & Figuras 3 a 5 \\
\hline 03/09/17 & $\begin{array}{l}\text { Manutenção da horta. Atividade bandeira do Brasil (com } \\
\text { crepom e explicação sobre o dia } 7 \text { de setembro e motivos } \\
\text { das cores da Bandeira). Atividade não concluída devido a } \\
\text { alterações internas de programação do Lar. }\end{array}$ & Figura 6 \\
\hline $15 / 09 / 17$ & Não fomos recebidas (motivo: visita do promotor). & - \\
\hline 22/09/17 & $\begin{array}{l}\text { Manejo da horta e atividade sobre o dia da árvore e a } \\
\text { primavera (desenho da árvore, caule com palito de sorvete, } \\
\text { frutos com botões de plástico e pintura indicando o xilema } \\
\text { e floema). }\end{array}$ & Figura 7 \\
\hline 06/10/17 & Manejo da horta e atividade livre com argila (animais). & Figura 8 \\
\hline $13 / 10 / 17$ & Manejo da horta e pintura dos animais feitos com a argila. & - \\
\hline $27 / 10 / 17$ & $\begin{array}{l}\text { Manejo da horta e plantio de alface e cebolinha com as } \\
\text { crianças do Lar. }\end{array}$ & Figuras 9 e 10 \\
\hline $03 / 11 / 17$ & $\begin{array}{l}\text { Atividade terrário e condução da horta após } 2 \text { meses do } \\
\text { plantio. }\end{array}$ & Figura 11 \\
\hline 09/11/17 & $\begin{array}{l}\text { Desenho das plantas e animais da fazenda (livro). Teatro } \\
\text { do livro (biblioteca do Lar) animais marinhos e teatro dos } \\
\text { três porquinhos (está foi uma atividade livre onde as } \\
\text { crianças escolheram os livros). }\end{array}$ & Figura 12 \\
\hline $17 / 11 / 17$ & $\begin{array}{l}\text { Plantio das mudas de alface e atividade livre: história da } \\
\text { cartilha do Zinho, Ed. Ambiental (IPEC, 2012). }\end{array}$ & - \\
\hline $24 / 11 / 17$ & $\begin{array}{l}\text { Encerramento com manejo da horta (produção e } \\
\text { funcionamento) e panfletos de Educação Ambiental } \\
\text { educativos sobre como cuidar do Meio Ambiente. }\end{array}$ & - \\
\hline
\end{tabular}

Fonte: A autora 


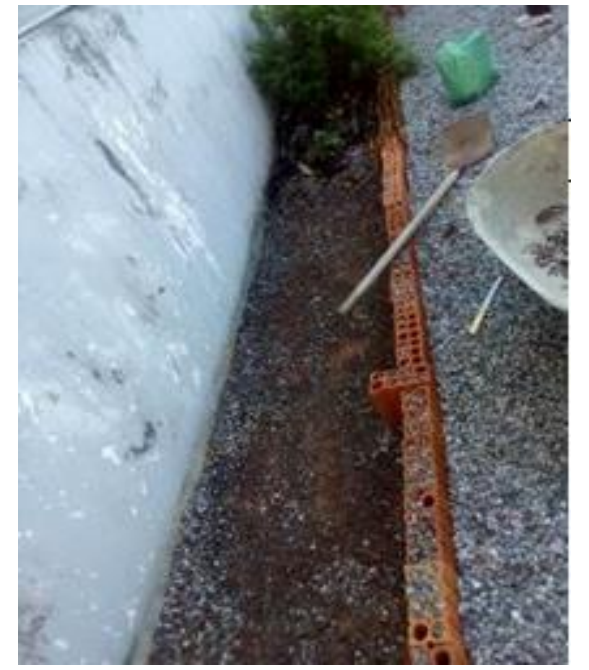

Figura 1: Início da realização da horta, retirada das pedras do local destinado ao plantio.

Fonte: Rosário (2017)

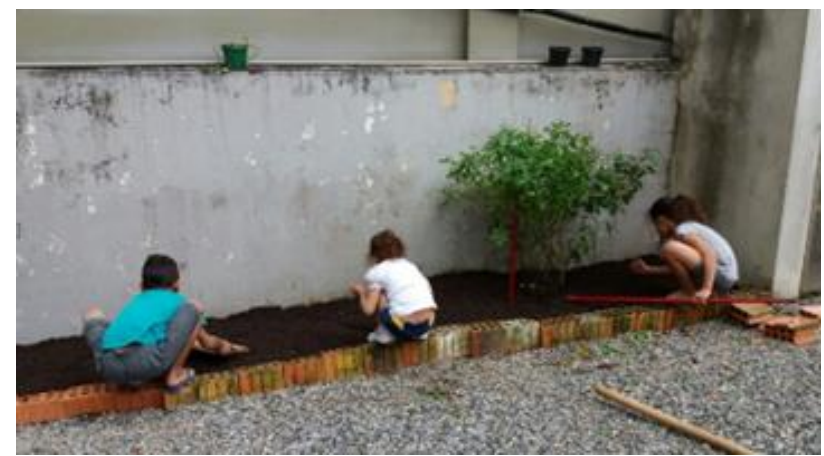

Figura 3: Implantação da horta (deposição de terra e nivelamento).

Fonte: Rosário (2017).

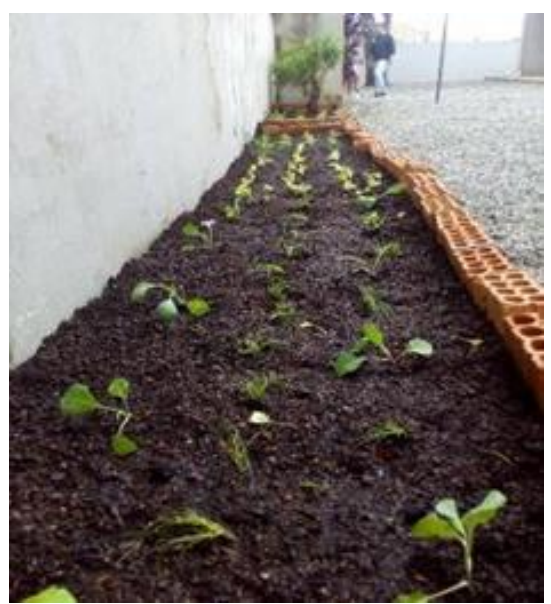

Figura 5: Horta depois da finalização do plantio das diferentes hortaliças.

Fonte: Rosário (2017).

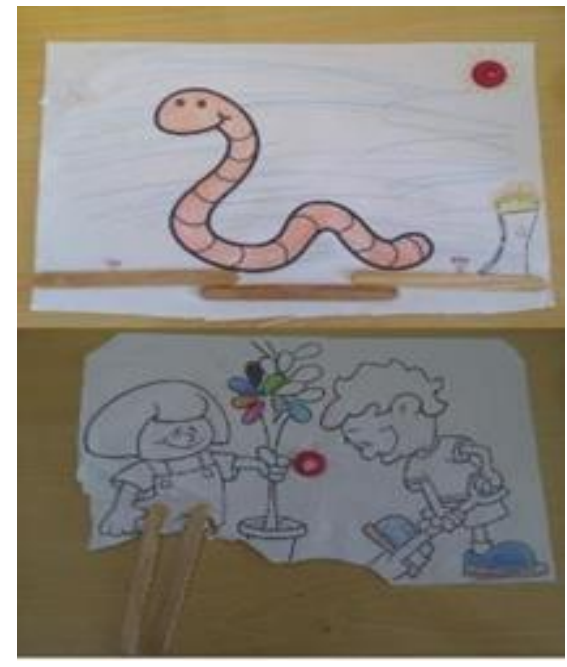

Figura 2: Atividades de desenhos para pintar relacionados à manutenção da horta. O desenho da boneca com pernas foi alterado por uma criança de 5 anos que as substituiu com palitos.

Fonte: Rosário (2017)

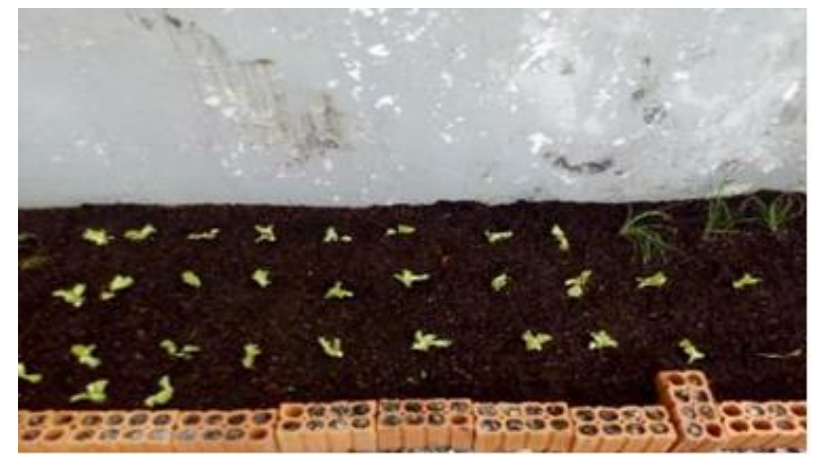

Figura 4: Mudas de alface e cebolinha plantadas pelas crianças no canteiro já preparado.

Fonte: Rosário (2017).

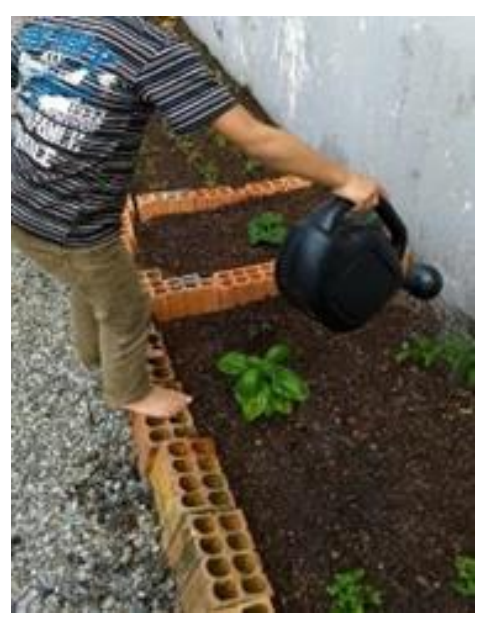

Figura 6: Manutenção (irrigação) da horta sendo realizada pelas crianças.

Fonte: Rosário (2017).

Revbea, São Paulo, V. 14, № 3: 155-168, 2019. revista brasileira

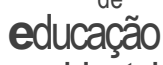
ambiental 


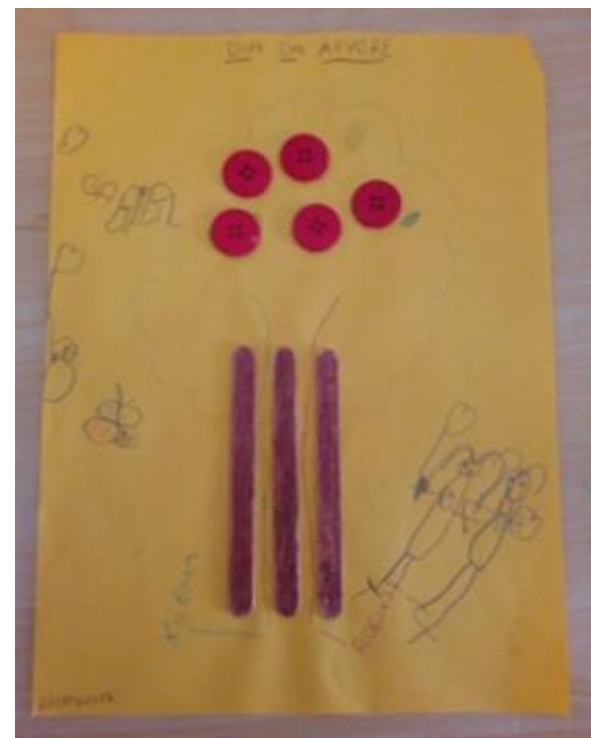

Figura 7: Atividade do dia da árvore indicando os sistemas condutores de água (xilema) e açúcares (floema), elaborado por uma das crianças.

Fonte: Rosário (2017).

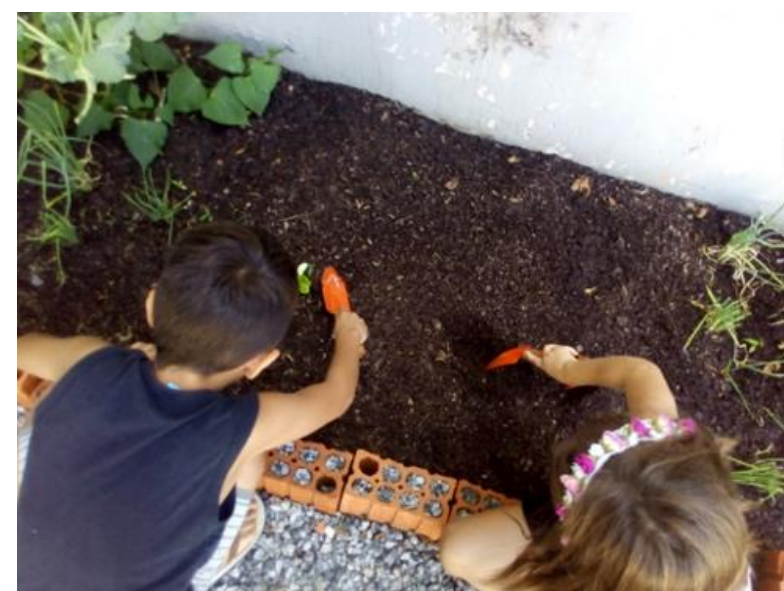

Figura 9: Manejo da horta sendo realizado pelas crianças com as ferramentas compradas para a atividade.

Fonte: Rosário (2017).

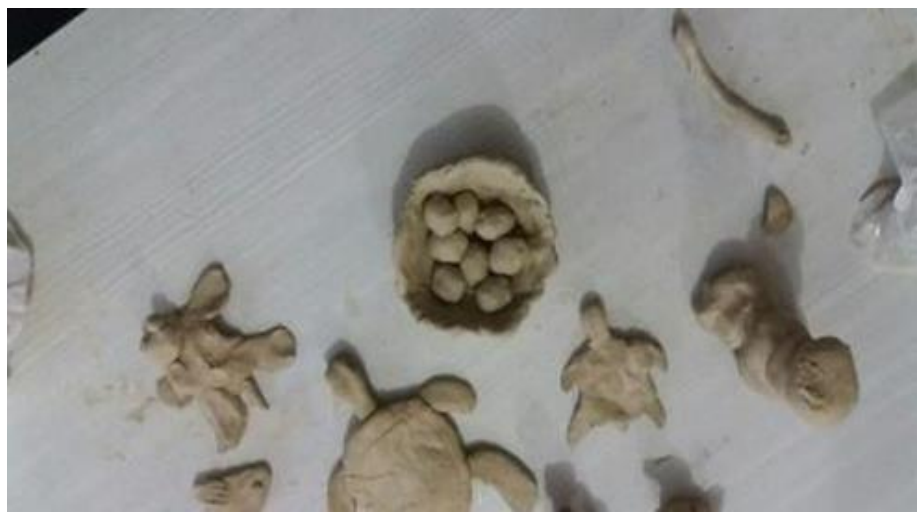

Figura 8: Atividade livre realizada com argila pelas crianças (esculturas de animais).

Fonte: Rosário (2017).

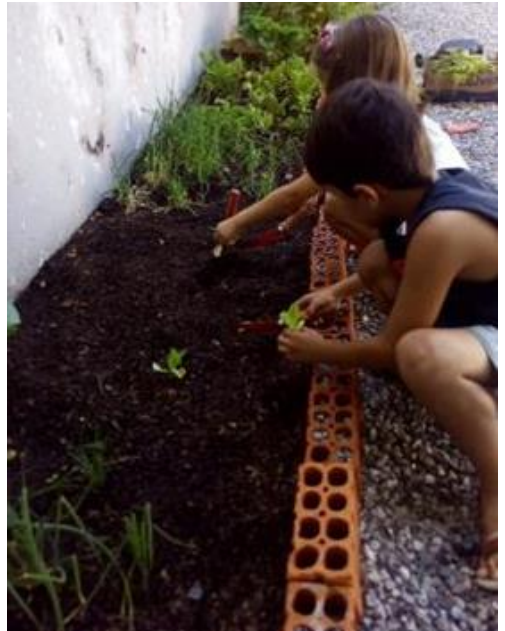

Figura 10: Manejo e plantio das mudas de alface e cebolinha realizado pelas crianças.

Fonte: Rosário (2017). 


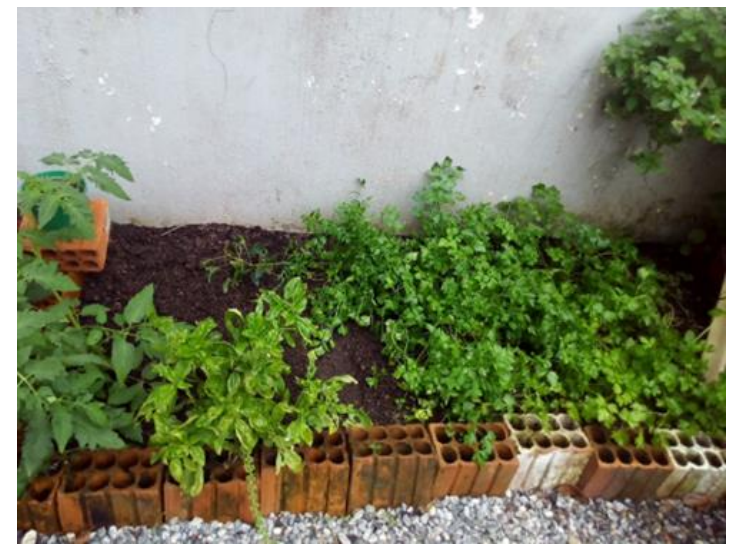

Figura 11: Aspecto da horta após 2 meses de manutenção.

Fonte: Rosário (2017).

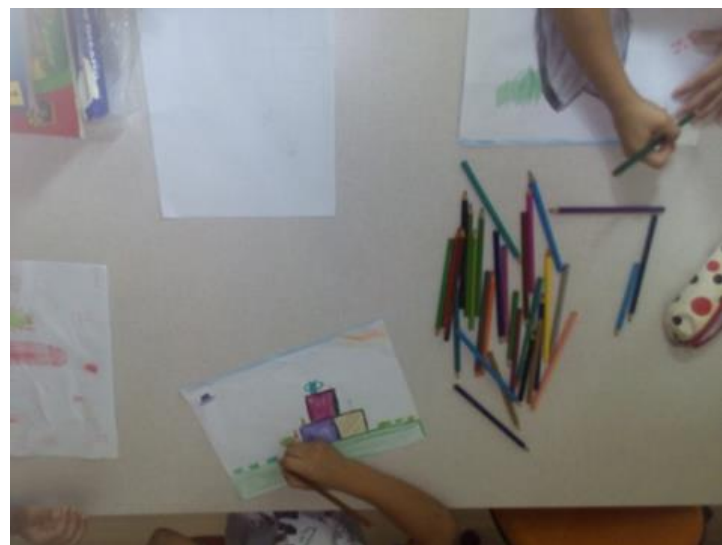

Figura 12: Desenho das plantas e animais da fazenda, elaborado pelas crianças após a leitura de história do livro disponível na biblioteca do Lar.

Fonte: Rosário (2017).

\section{Discussão}

É importante salientar que neste estudo o educador vai além dos autores deste projeto, pois todas as cuidadoras do Lar Criança Feliz são educadoras, transmitindo ensinamentos da educação informal que, segundo Trilla (1993), é uma educação não dominante e sem especificidade. A cada visita e procedimento realizado as crianças aprenderam, na prática, como efetivar o plantio, revolvimento da terra e manutenção da horta. Esta interação foi de muitas dúvidas, geradoras de diversas perguntas que foram sanadas por repostas práticas ao realizar as atividades descritas no Quadro 1. Como exemplos desta interação, podemos citar os questionamentos sobre o porquê das minhocas ajudarem as plantas, o porquê de se preparar a terra para plantar, o porquê de se molhar todos os dias as plantas, o porquê de o passarinho roubar as mudas e sementes da horta e o porquê de não matar as lagartas e os animais considerados feios.

Todas as perguntas feitas pelas crianças foram respondidas realizando $o$ procedimento prático, sob os cuidados da autora e da voluntária deste projeto. A minhoca foi colocada na terra para visualização e manejo pelas crianças para melhor entendimento de que estes organismos revolvem a terra e se alimentam de material orgânico encontrado nela, enriquecendo a terra para o bom desenvolvimento das plantas. Neste contexto analisado o preparo da terra foi compreendido e as crianças assimilaram que uma terra enriquecida com material orgânico gerado pelas minhocas daria uma plantinha bonita e maior. $\mathrm{Na}$ sequência, aprenderam que sem a água a minhoca ressecaria e morreria, pois, não conseguiria manter suas funções vitais e, consequentemente, revolver a terra. Também foi compreendido que as plantas também precisam de água na quantidade correta para o seu crescimento, além de ser explicada a forma de transporte dos líquidos no seu interior através dos vasos condutores (Xilema condutor de água e Floema condutor de alimento). Para Mendonça (2015), em contato com o meio externo, natureza ou ambiente similar, o ser

revista brasileira 
humano é integralmente estimulado, sendo essencial que as crianças tenham o direito à convivência com os outros seres vivos com os quais elas sentem grande proximidade. Já Saldanha (2016), cita que um dos principais objetivos da Educação Ambiental e mostrar que somos parte dele e completamente dependente também.

Durante as práticas era realizada uma analogia entre o ser humano e o ser estudado (planta ou animal), comparando sempre o que ocorreria com cada criança caso ela ficasse sem água, comida e proteção. Através desta comparação, foi possível a compreensão da necessidade de cuidar do meio ambiente, das responsabilidades que temos com os seres vivos e das consequências (negativas ou positivas) das nossas atitudes. As vivências com a natureza, segundo Mendonça (2015), devem cultivar a conexão que a criança já tem e conservar sua essência, tornando-a um forte aliado da educação do ser humano integral. Para Luzzi (2012), a educação deve produzir sua própria transformação fazendo os educandos refletirem sobre a falta de conhecimento existente e motivar um pensamento compreensivo, complexo e aberto a dinâmica de um conhecimento inacabado em permanente processo de construção.

$\mathrm{Na}$ manutenção da horta, em um primeiro momento, a interação com os passeriformes foi negativa, pois as crianças ficaram espantadas e contrariadas pelo fato das aves como sabiás e bem-te-vis se alimentarem das sementes e mudas que foram plantadas na horta. Entretanto, foi explicado que as aves também são importantes por levarem as sementes para outro ambiente, ajudando as plantas a crescerem em outros lugares. Também foi comentada a forma de disseminação, onde a ave iria defecar a semente, perdê-la ou soltá-la durante seu voo, ajudando na dispersão e manutenção da flora. Adicionalmente, foi solicitada às cuidadoras do Lar que colocassem algumas frutas próximas a horta, para que as aves não interferissem no crescimento das pequenas mudas da horta. Essa ação possibilitou a discussão e a ampliação das noções de convívio harmônico dos diferentes seres na proposta de trabalho realizado junto às crianças.

Um dos pontos fortes deste trabalho foi a compreensão do porquê não matar a lagarta, que até então era vista como um animal prejudicial e sem importância. Esta situação foi um elo achado no próprio pensamento de análise crítica das crianças, após várias perguntas geradas pelas educadoras (autora e voluntária). As crianças foram instigadas a perceber que, pelo fato de a lagarta não poder se defender e se expressar como os seres humanos, ela só teria como proteção as suas cerdas, liberando uma toxina que poderia causar pequenos ou graves acidentes. Assim, houve a percepção que as lagartas não são más, pois apenas estariam se protegendo para completar seu ciclo de vida, virando lindas borboletas ou mariposas que polinizariam muitas flores e nos dariam a beleza e graça da vida colorida das plantas.

Esse foi o esclarecimento mais bem-sucedido, pois logo após a compreensão, as crianças perceberam que podiam gostar das lagartas sem 
precisar tocá-las ou machucá-las, respeitando o espaço dos animais e contemplando-os, entendendo que cada ser tem seu papel fundamental no equilíbrio da natureza. A atividade proporcionou às crianças a compreensão de que, mesmo a lagarta não sendo o animal mais carismático, matar ou denominar algo como sendo feio ou ruim é uma questão de preconceito, pois se tratava de um assunto pelo o qual ainda não tinham conhecimento. Após a realização desta aula sempre que as crianças iam falar sobre um animal, eles nos olhavam pensativos e refletiam antes de qualificá-lo como ruim, feio ou mau. Para Mendonça (2015), o encantamento do conhecimento e do fenômeno natural é fundamental para formar o alicerce de qualquer conhecimento. É necessário complementar conhecimento teórico e experiência prática, pois estar em vivência com a natureza é uma experiência tão importante como o próprio conhecimento que se tem dela. No estudo de Freitas, et al. (2016) há citação de que o desenvolvimento da pessoa se dá pela interação entre a bagagem biológica e a bagagem cultural mediada por sujeitos do contexto social no qual está inserida.

Foi observado que as crianças absorveram os ensinamentos, uma vez que interrogavam suas cuidadoras diante de comportamentos contrário aos que havia sido aprendido, ensinando-as a não praticar determinadas condutas por não estarem de acordo com o que foi desenvolvido nas práticas e metodologia de ensino da conservação ambiental aplicadas. Um exemplo pôde ser dado pelos relatos frequentes de que elas não tinham molhado as plantas da horta devido ao adulto/cuidadoras não os acompanhar ou não permitir a rega nos momentos programados para esta atividade. Segundo Silva (2016), aprender é estar integrado ao ambiente e as pessoas. É importante que as boas atitudes sejam um estímulo e exemplo para outras pessoas no seu dia a dia, mesmo que objetivo principal não seja instruí-las. Dourado e Belizário (2012), citam que o educador precisa saber ouvir e valorizar o conhecimento intuitivo e experimental que se consolida no cotidiano.

Outro questionamento das crianças foi o porquê de os adultos não fazerem o que elas aprenderam. Uma vez que internalizaram os ensinamentos sobre a importância de todas as formas de vida e da necessidade de preservação das espécies, independentemente de sua aparência ou periculosidade, algumas crianças repreenderam as cuidadoras quando essas agiram de forma equivocada, eliminando as lagartas que estavam em algumas árvores do quintal do Lar. Tal fato merece destaque, pois apesar de as cuidadoras objetivarem a segurança das crianças com essa atitude, ressalta-se a importância para que as situações cotidianas sejam aproveitadas no processo educativo ambiental, evitando a desconstrução do que foi aprendido. Nesse caso, a situação de risco poderia ser aproveitada para que a criança fosse alertada sobre o perigo, porém ressaltado que o espaço do outro ser também deve ser respeitado. Segundo Saldanha (2016) o papel que o educador desempenha na construção, formação e princípios dos educandos em instituições é fundamental e fica claro quando observamos crianças preocupadas com pequenas atitudes que fazem toda diferença, como o 
descarte correto do lixo nas lixeiras por exemplo. No entanto, Silva (2016) relata que pensar na formação de um educador-cuidador sugere que ele precisa conectar seu conhecimento de vida individual com o aprendizado profissional, ou seja, voltado para o processo de formação continuada, compreendendo que o educador é um ser que está sempre estudando.

Mesmo com a compreensão e com o desenvolvimento do pensamento crítico das crianças sobre a temática desenvolvida, percebeu-se que, independentemente da faixa etária dos alunos, na ausência das educadoras, autora e voluntária do projeto, somente foi possível a manutenção dos ensinamentos adquiridos quando o adulto cuidador do Lar colaborava com o desenvolvimento e aplicação dos conhecimentos obtidos pelas crianças. Observou-se que papel do cuidador é de extrema importância para o processo contínuo da aprendizagem educacional geral. No momento em que o adulto cuidador se afasta do interesse de aprender juntamente com a criança, essa passa a reproduzir somente o que é oferecido para ela, tornando o trabalho de Educação Ambiental dificultoso, lento ou regressivo. Para Freire (1996), é importante entender que tanto o educador como o educando, são seres inacabados, portanto, estão sempre em processo de construção e reconstrução. No entanto, André e Zaremba (2015), relatam que ser educador social requer profundo preparo, e que a profissão não é regulamentada no Brasil. Muitas instituições exigem habilitação em Pedagogia, mas a maioria acaba exercendo o cargo de educador sem formação ou experiência.

\section{Conclusões}

O estudo demonstrou, diante de seus resultados, bases essenciais para educar e compreender o ambiente e suas formas de vida. O comportamento das crianças em todo processo de aprendizagem e práticas ambientais foi de interesse e participação ativa. O entendimento mútuo teve seu reconhecimento através dos valores ambientais por eles agregados e transpassados, que substancialmente será refletido em suas práticas de aprendizagens futuras elevando seus conhecimentos e valor ético a respeito das diversas formas de vida. É possível concluir que as crianças de idades distintas podem aprender e analisar através de um senso crítico de práticas educativas de diversos assuntos, alçando seus conhecimentos e comportamentos, despertando o sentimento sobre a necessidade da defesa e proteção das diferentes formas de vida.

As mudanças comportamentais também são gradativas e lentas, sugerindo a necessidade de um período maior e estável das ações de estudos como este. $\mathrm{O}$ acompanhamento e entendimento recíproco da criança e o adulto diante da educação é primordial para aceleração das melhorias na educação teórica, prática e moral em todas as idades. $O$ estudo esclarece que a melhoria no ensino prático infantil é quase que imediata quando está em conjunto com a compreensão dos adultos responsáveis. Porém, quando os adultos não colocam em prática os ensinamentos e entendimentos gerais, existe 0 fator 
reverso comportamental das crianças, pois elas se tornam aquilo que possuem, ou seja, são sujeitos reflexos do comportamento do adulto responsável.

Observou-se que aprender foi um ato de ouvir, ver, analisar, criticar e praticar, mas quando estes fatores estavam restritos somente as crianças, o processo educativo correu grande risco de ser só mais um método aplicativo, pois a grande mudança precisa ocorrer no ser adulto, amadurecido e de ideias ultrapassadas, pois são eles os grandes processadores de ensinamentos de bases da insciência.

Sugere-se que todas as ações diante de um processo educativo em qualquer instituição não escolar, sejam escolhidas, avaliadas e implantadas pelos seus gestores buscando-se profissionais técnicos habilitados (magistério, cursos pedagógicos, formação continuada) que estejam amparados por bases científicas e atualizados, dispostos para o desenvolvimento e para a execução da Educação Ambiental.

\section{Agradecimentos}

Ao Lar Criança Feliz de Itajaí/SC pela oportunidade para a realização do trabalho, a minha amiga e voluntária Vanessa M. Martins e ao Daniel F. Paz, pessoa mais importante da minha vida.

\section{Referências}

BRASIL. Ministério de Educação e Cultura. Lei no 9795, de 27 de abril de 1999. Dispõe sobre a Educação Ambiental, institui a Política Nacional de Educação Ambiental e dá outras providências. Brasília: MEC, 1999.

DELORS, J. Educação: um tesouro a descobrir: Relatório para a Unesco da Comissão Internacional sobre educação para o século XXI. Brasília: ed. Cnpq ibict unesco, p. 31, 2010. 41 p.

DOURADO, J.; BELIZÁRIO, F. (org). Reflexão e Práticas em Educação Ambiental: discutindo o consumo e a geração de resíduos. São Paulo: ed. Oficina de Textos, p. 108, 2012. 175 p.

EDUCAÇÃO AUSTRALIANA. Escolas (Futuros sem limites, Austrália). Disponível em: <https://www.studyinaustralia.gov.au/portuguese/australianeducation/schools-in-australia/>. Acesso em: 11 ago. 2017.

EEVA-LIISHALLANARO, M.S.C. A Proteção Ambiental na Finlândia. Embaixada da Finlândia, Brasília; Consulado da Finlândia, São Paulo. 20 agosto 2009. Disponível em: <http://www.finlandia.org.br/public/default.aspx? contentid=124097/>. Acesso em: 11 ago. 2017.

FREIRE, Paulo. Pedagogia da autonomia: Saberes necessários à prática educativa. São Paulo: ed. Paz e Terra, p.15-74, 1997. 144 p.

FREITAS, M.F.R.L.; PINTO, O.R..; FERRONATO, F.R. Psicologia da Educação e da Aprendizagem. Londrina: editora e distribuidora educacional. S.A, p. 34, 2016. p.192. 
IPEC Instituto de Pesquisas Cananéia. Guia de Educação Ambiental: A Turma do Zinho. 2. ed. Cananéia: Projeto Boto Cinza, 2012. 30 p.

JADSON, A.; ZAREMBA, F. Educadores sociais têm função importante, mas profissão não é regulamentada. Lições para vida, Tribuna Paraná, Paraná, $\quad 18$ setembro $2015 . \quad$ Disponível em: $<$ http://www.tribunapr.com.br/noticias/parana/educadores-sociais-tem-funcaoimportante-mas-profissao-nao-e-regulamentada/>. Acesso em: dez. 2017.

LIBÂNEO, J.C. Pedagogia e Pedagogos, Para Quê? 7. ed. São Paulo: ed. Cortez editora, p.25, 2004. 208 p.

LUZZI, D. Educação e Meio ambientes: Uma Relação Intrínseca - Série Sustentabilidade. Barueri: ed. Manole, p.18, 2012. 187 p.

MARANGON, C. Preservar também é coisa de criança. Gestão Escolar, Nova escola Notícias, 01 de dezembro 2002. Disponível em: $<$ https://novaescola.org.br/>. Acesso em: 04 ago. 2017.

MENDONÇA, R. Atividades em áreas naturais [livro eletrônico] / Rita Mendonça. São Paulo: Instituto Eco futuro, p. 11-99, 2015. Disponível em: $<$ http://www.ecofuturo.org.br/blog/atividades-em-areas-naturais $>$. Acesso em: 04 ago. 2017.

NEVES, L.R. Pedagogia social e psicologia: Diálogos possíveis na educação não formal. Rev. Paidéia, FUMEC. Belo Horizonte, v. 5, p. 102, 2008. 118 p.

NUNES, T. Educação Ambiental pode virar disciplina obrigatória nas escolas. Ponto Biologia, 2017. Disponível em: <http://pontobiologia.com.br/ educacao-ambiental-disciplina-obrigatoria/>. Acesso em: 13 abr. 2018.

SAMPAIO, A.G..; MOURA, F.M.T. Educação Ambiental como disciplina curricular: Possibilidades formativas. Universidade Estadual do Ceará: Revista da SBEnBIO - Número 7, p. 436, 2014.

SALDANHA, C.B. Educação Ambiental. Londrina: editora e distribuidora educacional. S.A., p. 10-202, 2016. 216 p.

SALLES, C. Meio Ambiente e Educação Ambiental nas Escolas Públicas. Disponível em:<https://carollinasalle.jusbrasil.com.br/artigos/112172268/meioambiente-e-educacao-ambiental-nas-escolas-publicas/>. Acesso: 04 ago. 2017. SALVADOR, C.C.; MESTRES, M.M.; GOÑI, J.O.; GALLART, I.S. Psicologia da Educação. Porto Alegre. ed. Artmed, p.142-143, 1999. 214 p.

SILVA, A.D. Didática: planejamento e avaliação. Londrina: editora e distribuidora educacional. S.A., p. 52-102, 2016. 216 p.

TELLES, M.Q.; ROCHA, M.B.; PEDROSO, M.L. Vivências Integradas com o Meio Ambiente: Práticas de Educação Ambiental para Escolas, Parques e Zoológicos. São Paulo. Editora Sá, p. 12-130, 2002. 144 p.

TRILLA, J.; BERNET J.T. (org). La educación fuera de la escuela. Ambitos no formales y educación social. Barcelona. ed. Ariel, p. 23-27, 1993. 276 p. 